\title{
Существуют ли общечеловеческие ценности? (Диалог, посвящённый семидесятилетию доктора философских наук, профессора С.Е. Ячина)
}

В марте 2021 г. глава философрккой школы Дальневосточного федерального университета и член редакционной коллегии "Ойкумены", д. фрилос. н., профрессор департамента фрилософии и религиоведения ДВФУ Сергей Евгеньевич Ячин отметил знаменательный юбилей - свое семидесятилетие. По пожеланию самого юбиляра, празднование нашим журналом этого важного для всей дальневосточной науки события было решено провести в деловом, рабочем режиме - в формате диалога Сергея Евгеньевича со своими учениками и коллегами по вопросам, находящимся в фокусе его сегодняшних исследовательских интересов.

Конончук Д.В.: Уважаемые коллеги! Уважаемый Сергей Евгеньевич! Наш нынешний разговор посвящен проблеме ценностей. Как известно, вы предпочитаете мыслить в парадигме, заданной хайдегерианским вариантом феноменологии. Сообразно данной парадигме, ключевым концептом к пониманию человеческого бытия вы полагаете не ценность, а смысл. Два года прошло с момента издания вашей книги "Критика аксиологического разума"1, в которой подробнейшим образом рассмотрена проблема соотношения ценности и смысла. Отсюда вопрос: изменилось ли с тех пор ваше виденье проблемы данного соотношения?

Ячин С.Е.: Прежде всего, коллеги, хочу выразить вам свою признательность за проявленное ко мне внимание и, конечно же, не в плане персональном, а как внимание к тому, о чем мне приходится думать и писать. Делясь своим опытом письма, скажу, что любая книга может писаться бесконечно. То есть ты кругами ходишь вокруг одной и той же проблемы, постоянно хочешь ее дополнять, и если когда-то решил её публиковать, то только потому, что у тебя возникает такая "техническая необходимость" когда-то поставить точку. Но основная мысль все равно сохраняется. Да, многое бы хотелось уточ-

1 Ячин С.Е. Критика аксиологического разума: монография. М.: ИНФРА-М, 2018. 137 с. URL: http:// znanium.com/catalog/product/958500. См. также статьи: Ячин C.E. Критика аксиологического разума // Вопросы философии. 2017. № 8. C. 54-68. URL: http:// vphil.ru/index. php?option=com_content\&task=view\&id=1728\&Itemid=52; Yachin Sergey E. Critique of Axiological Reason: Why the Idea of Values has Achieved the Totality in Modern Culture // International Journal of Philosophy. 2019. Vol. 7. No. 1. P. 31-40. URL: http:// www.sciencepublishinggroup.com/journal/ paperinfo?journalid $=204 \&$ doi $=10.11648 / j$.jpp. 20190701.15

\section{(C) Ячин С. Е., Конончук Д. В., Киреев А. А., Левшин С. В., Котова Д. Д., 2021}

ЯЧИН Сергей Евгеньевич, д-р филос. наук, профессор департамента философии и религиоведения Дальневосточного федерального университета (2. Владивосток). E-mail: yachin.se@dvfu. $\mathrm{ru}$

КОНОНЧУК Дмитрий Васильевич, канд. фрилос. наук, доцент департамента фрилософии и религиоведения Дальневосточного федерального университета (ә. Владивосток). E-mail: Novymladshy@yandex.ru

КИРЕЕВ Антон Александрович, канд. полит. наук, доцент кафедры политологии Дальневосточного федерального университета (2. Владивосток). E-mail: antalkir@yandex.ru

ЛЕВШИН Сергей Вячеславович, старший преподаватель департамента фрилософии и религиоведения Дальневосточного федерального университета (2. Владивосток). E-mail: levshin.sv@ dvfu.ru

КОТОВА Диана Дмитриевна, магистрант Дальневосточного федерального университета (с. Владивосток). E-mail: kotova.ddm@students.dvfu.ru 
нить, изменить, но основную мысль я, конечно, сохраняю. Эта мысль состоит в том, что современная эпоха и современный человек утратили отчетливое чувство и понимание различения, которое было определяющим для античного и средневекового мышления. Утрачена ясность различения того, что "дает нам жизнь": в те времена это именовалось "благо" и "благодать", - того, "что мы считаем за благо", т.е. наших собственных ценностей (я использую фрормулы Платона и Аристотеля). Благо и ценность - это два безусловно связанных, но связанных как два противоположных полюса человеческого бытия-в-мире. А другой стороной утраты ясности различения блага и ценности является возникшая путаница с категориями смысл и ценность. Именно в этом аспекте я опираюсь на онтологическую герменевтику Хайдеггера, который установил онтологический приоритет понимающего отношения человека к миру. Понимание - это не способ познания как таковой, но сам способ бытия человека в мире. Человеческое бытие - это понимающее бытие, понимающее бытие, говорит Хайдеггер, это понимание смысла. И когда с этой точки зрения мы начинаем смотреть на проблему ценностей, то они находят свое законное "производное место": человек сначала понимает смысл сущего и только потому оценивает его. Я ни в коей мере не оспариваю значения ценностей в мире человека, но всегда настаиваю на том, что мы прежде понимаем и только потом что-то ценим. Это различение является принципиально важным. Моя книжка начинается с обращенного к читателю теста, задавая ему вопрос - если у вас есть любимый человек, вы готовы его назвать ценностью? Я этот вопрос много раз опробовал в студенческой среде и уже знаю ответы: приблизительно $3 / 4$ и даже больше положительно отвечают на этот вопрос. Для них нет ничего странного назвать любимого человека, ребенка - "это моя ценность". Но у остальных возникает подозрение: здесь что-то не так. Мы не можем назвать любимое ценным. Почему? А потому что его нельзя ставить в положение оценки, в позицию сравнения. И вот эта глухота современного человека к этому различению блага и ценности меня не то чтобы сильно тревожит, но я воспринимаю это критически, как некоего рода эпохальный недостаток нашего времени.

Но если бы я сейчас вернулся к проблеме и заново переписал бы книгу, то внес бы в неё или расширил некоторые сюжеты. Я бы уделил больше внимания историко-фрилософрскому контексту становления идеи ценности. Мне бы хотелось сказать не только о том, почему для античной и средневековой мысли ценность не являлась значимой категорией, но и том, почему в современной философии (во всех её значимых направлениях: в френоменологии, герменевтике, в экзистенциализме, в аналитической фрилософрии) она занимает достаточно скромное место. Я сам коротко отвечу на этот вопрос. Во-первых, в силу антропологической установки философии самого Канта (и в разрез неокантианской версии фрилософиии культуры) и, во-вторых, в силу того лингвистического поворота в фрилософрии вообще (и в фрилософрии культуры - в частности), который просто не оставляет достаточно весомого места для идеи ценности. Философрское внимание к языку задает смысловую, а не аксиологическую интерпретацию культуры.

Конончук Д.В.: Спасибо, Сергей Евгеньевич. Со своей стороны напомню, что, как утверждал Хайдеггер, "язык говорит". Заметьте, слово "драгоценный" имеет иронический оттенок.

Ячин С.Е.: Да, именно поэтому слово "дорогой мой" - нейтральное, и выражает то, что выражает. А когда ты говоришь любимому "бесценный мой" в этом есть некая ирония - это именно про то.

Киреев А.А.: Что следует понимать под бытием ценностей? И, исходя из этого, следует ли рассматривать общечеловеческие ценности как некую данность или как долженствование? Или же это противопоставление данности и долженствования ложно?

Ячин С.Е.: Собственно, в этом и состоит философрская проблема. Философркая теория ценности возникла (в неокантианской версии) как попытка обоснования объективного (хотя и трансцендентального) характера ценностей. Ценности стали пониматься не как то, что человек ценит (считает ценным для себя), но как особый род бытия. Моё критическое замечание в адрес такого хода мысли состоит в том, что при такой объективации ценностей мы в одном понятии смешиваем две принципиально разные ситуации: ценность 
как то, что является объективным и необходимым условием человеческой жизни (и жизни вообще), и то, что служит нам предметом оценки, то, что мы считаем за ценность. Это различение было вполне ясным для античной и средневековой мысли: то, что, существуя само по себе, "дает нам жизнь", они называли благом (и до сих пор мы так говорим о естественных благах жизни: о солнце, воздухе, воде и т.п.), и то, "что мы считаем за благо" (так у Аристотеля). Мой пример - это родной язык, благодаря которому мы обретаем человеческую разумную жизнь. Язык - основное благо культуры. Почему бы нам не назвать язык "ценностью культуры"? Потому, что при таком понимании, мы не сможем категориально различить "дарующее нам человеческую жизнь" и то, что для нас служит предметом выбора и оценки. Если использовать слова "данность" и "должное", то благо - это данность жизни (для жизни), а ценность - то, что мы считаем должным для неё. При этом благо может быть еще и особой ценностью (безусловно, есть те, для кого родной язык представляет особую ценность), но не наоборот: некоторые ценности могут не быть благом для жизни. Поэтому различение и даже противопоставление данного (как блага) и должного (как ценности) не только не является ложным, но прямо наоборот: их неразличение является ложным ходом мысли и приводит к невообразимой путанице понятий.

Киреев А.А.: Когда вы говорите о благе, это и есть некая данность, нечто, не зависящее от выбора человека? Он внутри этого блага пребывает, он создан этим благом?

Ячин С.Е.: Именно так.

Киреев А.А.: Можно ли сказать, что общечеловеческие ценности укоренены в данности, что они причастны благу? Или они есть следствие некоего выбора и долженствования?

Ячин С.Е.: Никаких общечеловеческих ценностей в смысле обязательных предметов оценки и выбора не существует. Вы всегда найдете человеческие общности, ценности которых будут радикально отличаться от ваших. Реальный смысл "общечеловеческих ценностей" (и разговоров о них) в том, что существуют некие данности, объективно необходимые для сохранения жизни на Земле. Есть реальная задача сделать так, чтобы эти данности (блага) стали ценностью для всех людей. Эта задача становится бессмысленной, если вы заранее объявляете, что вот это необходимое для совместной жизни на Земле уже является всечеловеческой ценностью.

Левшин С.Е.: Каково место ценностей в структуре мира, их онтологический или философркий статус? Иначе говоря, какое место они занимают в философркком дискурсе в контексте различия сущего и должного в рамках философского дискурса? То есть как нам, философам, работать в контексте различия сущего и должного?

Ячин C.Е.: Давайте еще раз обратим внимание на историческую логику появления фрилософрской теории ценностей. Как известно, её разработали неокантианцы в рамках философии культуры (им и принадлежит заслуга дисциплинарного формирования теории культуры в современном фрилософрском дискурсе). Но для Канта такая культурологическая постановка вопроса о ценностях была бы совершенно чуждой (на это обстоятельство указывает М. Мамардашвили). Почему? А потому что Кант понимал ценность как антропологическую, а не культурологическую категорию. Неокантианцы объективировали в область культуры то, что Кант считал сугубой привилегией субъекта и размещал в области практического разума и способности суждения. В этом отношении я остаюсь верным кантианцем и считаю, что дискурс ценностей следует оставить в области философской антропологии с учетом современного понимания "природы" человека. Современный дазайн-анализ и әкзистенциальная аналитика дают вполне достаточную рамку для понимания того, как возникают и как "работают" ценности.

Ценность, рассмотренная в антропологическом и френоменологическом ключе, видится производной от операции оценивания. Культурологический дискурс вольно или невольно разрывает эту связь и представляет ценности в гипостазированном виде, как самостоятельные сущности. Антропологический и феноменологический дискурсы подвергают деструкции (ставят по сомнение) сам аксиологический вопрос: "Что такое ценность?". Действительный вопрос должен быть поставлен иначе: "Что значит ценить?" (И это совершенно кан- 
товский вопрос). В духе аналитической строгости можно сделать еще и такое критическое замечание: не следует забывать, что слово "ценность" есть просто субстантивированный глагол.

Левшин С.Е.: Вы отметили закономерность возникновения категории ценностей в фрилософрском дискурсе от середины и конца XIX в. в связи с проблемой свободы, сюда же можно добавить проблему развития капитализма. И все же, как вы считаете, закономерная для истории фрилософиии категоризация ценностей в XIX в. - это фрилософрская ошибка забвения Бытия или прогрессивное явление?

Ячин С.Е.: Я действительно считаю, что выход проблематики ценностей на передний фронт фрилософрских размышлений является реакцией на закономерный результат "прогресса в сознании свободы" (используя гегелевский критерий). Сущностным основанием ценностного отношения человека к миру является свобода выбора, самым непосредственным образом явленная современным рынком и далее пронизывающее все остальные человеческие отношения. Но это на поверхностном уровне. По сути же, на передний план выхолит воля к власти в её ницшеанском понимании. Именно поэтому Хайдеггер считал Ницше подлинным создателем фрилософрии ценностей, тогда как неокантинацы, по его словам, "хромая, лишь следуют за ним". Философия обязана осмыслить это историческое движение человеческой экзистенции. Да, это движение сопровождается "забвением бытия", но я бы не стал называть это ошибкой. Забвение, как показывает аналитика исторического разума (это П. Рикёр), является обязательным ходом мысли, без которого она не сможет перейти на следующую ступень постижения полноты бытия (т.е. истины).

Конончук Д.В.: Сергей Евгеньевич, позвольте мне уточнить: означает ли то, что вы сказали, некую приходящую, историческую природу ценностей? То есть ценности существовали не всегда и, возможно, будут не всегда существовать в будущем? То есть неправомерно говорить: "ценности древнего грека" или "ценности древнего китайца"?

Ячин С.Е.: Нет, этого я не имею в виду. Ценностное отношение к миру имманентно для человека. Во все времена и во всех культурах человек имел ценности. Вопрос лишь в том, какое место в жизни человека и культуры занимала возможность свободного выбора среди благ жизни. Современный человек просто получил больше экономических возможностей и политических прав на выбор ценностей.

Котова Д.Д.: Скажите, существуют ли общечеловеческие эстетические ценности? И если таковые существуют - что именно мы можем к ним отнести?

Ячин С.Е.: Ответ на этот вопрос как раз потребует ясного различения категорий смысла и ценности. В эстетическом переживании или восприятии отчетливо проявляется специфическая смысло-ценностная двойственность. Само по себе эстетическое переживание (наслаждение красотой, например) сродни пониманию смысла слова или речи. Оно столь же безусловно и "нейтрально". Мы либо понимаем смысл речи, либо нет; мы либо переживаем красоту, либо нет. Если бы человек не обладал "по своей природе" способностью усмотрения красоты в мире, то он бы не увидел этот предмет как прекрасный. Но далее мы замечаем, что это чувство прекрасного имеет разную степень интенсивности и в этом отношении вещи имеют для разных людей разную эстетическую ценность (вспоминая майевтику Сократа: "Одним больше нравится любоваться лошадьми, а другим - девушками"). Желание красоты - общечеловечно, но вопрос о том, что именно вы считает красивым - зависит от обстоятельств судьбы и культуры. Более ясную картину нам дает другая экстатическая категория - категория комического. Способность видеть смешное и смеяться, яркая антропологическая черта всех людей и культур. Как таковая, эта способность никакого отношения к ценностям не имеет. Но какие ситуации вызывают смех - это сильно зависит от культуры. Вообще, мне думается, что использование аксиологической терминологии для сореры эстетического искажает понимание сущности эстетического переживания. Смеясь, сопереживая трагическому герою, вникая в сюжет повествования, мы ничего не оцениваем, мы просто испытываем специфическое эстетическое чувство, имеющее онтологическую, а не аксиологическую природу.

Котова Д.Д.: То есть, если я правильно понимаю, - смысл един, но ценности различны? Смысл есть некое пространство согласования ценностей? 
Ячин С.Е.: В том числе. Всё человеческое погружено в логику смысла.

Конончук Д.В.: Очевидно, что мы живем в мире, где существует многообразие культурных форм, равно как и существует целый ряд научных дисциплин со своими специфическими методами для изучения этих форм. В тоже время философрские концепции человека, в т.ч. и ваша концептуализация человека, призваны к познанию и осмыслению максимально общего, прояснению человеческой природы в целом, пониманию человека как такового. Как тогда возможна фрилософрская постановка вопроса о различии ценностных планов в зависимости от той или иной культуры? И чем такая постановка обуславливается?

Ячин С.Е.: На это у меня будет краткий ответ. Изначально на характер культуры определяющее влияние оказывала окружающая природная среда или, как её определяют, "вмещающий ландшафт". И именно эта зависимость человека от природы никогда изначально не осмыслялась в категориях ценности. Природа выступала для человека как то, что "даёт ему жизнь", т.е. как благо и благодать, к которому он должен относиться с благодарностью. Может быть, главный моральный урок важности различения блага и ценности, состоит именно в этом: то, что мы выбираем как ценность своей жизни не требует благодарности. Почему я должен быть благодарным тому, что я сам выбрал как ценную вещь на рынке, как спутника жизни (супруга), как ребенка, которого сами решили родить? Принцип ценности (если его категорически придерживаться) регулятивно исключает благодарность, верность и долг.

Киреев А.А.: Является ли существование человечества тем благом, которое лежит в основании общечеловеческих ценностей? Или бытие общечеловеческих ценностей вполне автономно по отношению к бытию человечества? Общечеловеческие ценности восходят к некоему благу или они самодостаточны?

Конончук Д.В.: В дополнение: существуют ли общечеловеческие ценности отдельно от человечества?

Ячин С.Е.: Я переставлю акценты первой части вопроса: может ли существование человечества стать общечеловеческой ценностью? Ведь безусловный приоритет блага существования всего человечества не является обязательным для всех. Можно занять и такую позицию: "Зачем нам этот мир, если в нём не будет (далее на выбор - "меня", "России" и пр.). Сказать, что ценности автономны по отношению к благу жизни, я не могу. Зависимость обратная. Благо - онтологическая, а не аксиологическая категория. Жизнь - она просто есть, и она нам дарована как благо. При этом вы её можете и не ценить, но вы не могли бы её "не ценить", если бы она уже не была вам дарована. Благо существует автономно от ценностей, а ценности так или иначе привязаны к благу, даже в плане отрицательного отношения к нему. Однако эта связь ценностей с тем или иным благом не является непосредственной, она опосредуется тем, как субъект понимает, что есть благо, т.е. зависит от смысла. Автономия ценностей возможна только потому, что ценности в истоке имеют онто-антропологическую, а не культурную природу. Культура только фриксирует результат генезиса ценностей.

Киреев А.А.: Ведь отнесенность "общечеловеческих ценностей" в той или иной конкретной их интерпретации к человечеству может быть мнимой, ложной?

Ячин С.Е.: В утверждении ценности того, что объективно вредит жизни, в негативно оценке того, что даёт вам жизнь, я действительно усматриваю некую мнимость и ложность. Такого рода утверждение и отрицание содержат в себе перформативное противоречие, поскольку они возможны только с позиции того, кто уже живет и мыслит.

Киреев А.А.: Если благо - это диапазон всех возможных ценностей, то возможны ли ценности вне этого диапазона, ценности, существующие автономно?

Ячин С.Е.: Одна из трудностей, с которой сталкивается "универсальная аксиология" как раз и состоит в том, как объяснить существование ценностей, которые не являются "действительными" ценностями для жизни как блага. Проблема возникает в силу того, что в аксиологии понятие блага рассматривается как вид ценностей. И в культурологической парадигме эта проблема неразрешима. Невозможно указать на критерий, который бы позволил разли- 
чить, какие ценности являются благими, а какие - губительными. Это можно сделать только в рамках антропологической парадигмы понимания того, как субъект создает свои ценности и, соответственно, устанавливая онтологический приоритет блага над ценностями. Автономия ценностей тогда будет непосредственным выражением автономии человека, негативной манифестацией его свободы.

Левшин С.Е.: От онтологии - к этике. Каково ваше понимание различия ценности и нормы: они тождественны, что-то первично/производно или существует их диалектическая взаимосвязь? Если последнее, то в чем эта диалектика заключается?

Ячин С.Е.: Только оставаясь в русле антропологического понимания ценностей, мы сможем проследить реальный генезис ценностей и норм, а также поймем необходимость их различения. Так же как ценности производны от процедуры оценивания, так и нормы производны от процедуры нормирования. Норма, в значительной части случаев, но не всегда, представляет собой институционально нормированную коллективную ценность. Совместная жизнь людей (а другой у нас нет) подчиняется логике объективации. Первичный слой жизни - слой непосредственных желаний, чувств, переживаний - как таковой еще не знаком с ценностью как объективированного экзистенциала жизни (здесь ценное тождественно желаемому). Ценность как категория может появиться только в слое символического, как то, что мы можем интерактивно обозначить "ценностью" перед лицом Другого. Символически маркированная "моя / наша ценность" может быть еще более социально объективирована для "совсем других" в виде нормативного правила, как норма данной культуры или общности. Заметим, однако, что в качестве нормы, учреждаемая ценность как раз и может утратить ценность с позиции многих членов социума. Краткая формула этой последовательности будет такова: "хочу - могу - должен/ имею право". (Примером может служить такая "ценность" как свобода слова: хочу сказать - могу/ умею сказать - имею право / должен сказать). Долженствования и права могут иметь место в социальной жизни преимущественно в нормированной форме, но как таковые в силу своей обязательности (как юридические законы, например) могут быть вообще не связанными с моральными ценностями.

Конончук Д.В.: Вопрос связан с вашей новой книгой "Желание Вечного. Этико-философский трактат", которая выходит в этом году. Мне посчастливилось видеть вашу книгу ещё до момента выхода, и с одним утверждением из нее и связан мой следующий вопрос: вы неоднократно говорите в своем трактате, что онтология имеет этические основания. Не кажется ли вам, что эта позиция обратна общепринятой? Онтология не может строиться на этике, напротив, - этика строится на онтологии. Ибо если онтология будет строиться на этике, то подобная позиция будет чревата выводом "мир устроен так, потому что мне этого хочется?"

Ячин С.Е.: Я говорю: "фрундирует", - не в смысле того, что желание, как модус бытия, предшествует самому бытию, но в том, что всякое учение о былтии (онтология) базируется на той или иной этике или, может быть - на моральной установке. У тверждая, что этика фрундирует онтологию, я имею в виду два, как мне кажется, очевидных обстоятельства. Во-первых, исторически философская (категориальная) рефлексия начинается с этической проблематики. Так, античная фрилософия имеет своё начало в "Дельфийском завете" ("познай самого себя"), который и в те времена, и в дальнейшем понимался преимущественно как этический принцип. Только позже античная фрилософия дорастает до своего канона единства этики, фризики (она же онтология) и логики. Философская мысль в своем движении от мифра к логосу не сразу целиком отпочковывает свои категории от образно-ассоциативного мифологического мышления. Первым, по мере выделения человеком себя из природы, как раз и формируется учение о должном для человека. Некоторые онтологические интуиции возникают и на этом этапе, но какого-либо категориального статуса еще не имеют. Во-вторых, та же закономерность соблюдается в личном становлении фрилософра. Если мы соглашаемся с тем, что "фрилософия - личное дело философствующего и она должна состоятся как его собственная мудрость" (так, по словам Э. Гуссерля) или же с тем, что она является (помимо прочего) опытом самопознания (особенно подчеркнуто Э. Кассирером), то 
отсюда и следует, что собственный этос фрилософра фрундирует ту онтологию, которую он позже создает. Только этим и можно объяснить, почему каждый великий философ создает свою онтологию. Он создает систематическое учение о мире-в-целом для обоснования той системы значений (в том числе - ценностей), в которых лично убежден, в которые верит, которые представляют для него личную ценность. По своему категориальному составу онтологии (в одной культурной традиции) достаточно близки, но значение каждой из категорий в систематическом учении могут радикально отличаться (как например в теологических, пантеистических и атеистических онтологиях). Это различие как раз и обусловлено тем, что исходно фрилософы занимают разные этические позиции, имеют своё представление о должном для человека, а значит и о его месте в Мире.

Киреев А.А.: С точки зрения внутреннего содержания азиатских и западных ценностей, какая перспектива их отношений является наиболее вероятной - параллельное существование, антагонистическая борьба или их генерализация в направлении "блага человечества"?

Ячин С.Е.: Современная технологическая цивилизация является той "естественной средой", которая сближает ценности разных культур. Это показывают и мировые сравнительные исследования ценностей. Основное различие культур восточного и западного типа проходит по оси "индивидуализм-коллективизм": семейные, религиозные, политические, гендерные ценностные ориентиры так или иначе восходят к тому, как человек (респондент) понимаем своё место в обществе, в коллективе, в семье, в государстве и пр. Мы наблюдаем, как традиционный коллективизм восточных культур "мигрирует" в сторону ценностей личной (приватной) жизни, но и западные "либеральные ценности" движутся в сторону коллективизма. Так, отчетливую коллективистскую позицию занимают социал-демократическое (достаточно влиятельное) движение в Европе. Я замечаю, что зоной смыслового единства становится концепция коммунитаризма, возникшее в интеллектуальной среде Запада и уже получившее поддержку среди интеллектуальных и политически элит на Востоке. Поэтому думаю, что перспективной является генерализация общих ценностей. ей"?

Киреев А.А.: Можно ли это назвать "экономической рационализаци-

Ячин С.Е.: С оговорками: я бы сказал с учетом того, что в самой экономике произошел антропологический и культурный поворот. Если исходить из того фракта, что современная экономика - это экономика знаний, в которой решающее значение имеет человеческий, креативный потенциал, то это "экономическое обстоятельство" действительно детерминирует сближение культур. Современная экономика действительно подчеркивает значение человека как личности.

Конончук Д.В.: Развивая идею Антона Александровича об "экономической рационализации ценностей", можем ли мы пойти ещё дальше и говорить о некоем актуальном или потенциальном производстве ценностей?

Ячин С.Е.: Именно так. Современные массмедиа (экономическое значение которых сегодня колоссально) в буквальном смысле производят образы желаемой жизни и потому непосредственно влияют на эстетические, моральные, политические установки аудитории. Однако общий эффеккт такого производства не является тотальным. Мы имеем дело с обычным товарным рынком медийной продукции. Потребитель этой продукции имеет стандартную свободу выбора, имеет принципиальную возможность получать информацию из разных источников, питаться от разной системы ценностей. Каждый производитель медийной продукции, конечно же, хочет завоевать аудиторию, но скажем так: "хочет то он хочет, но кто же ему даст" (понятно, что я говорю о странах современной демократии).

Конончук Д.В.: Можем ли мы сказать, что современная массовая культура - это фрабрика по производству ценностей?

Ячин С.Е.: Да, это фабрика, но работающая в условиях очень сильной конкуренции. Когда потребитель на рынке имеет возможность сравнивать предлагаемые ему "духовные ценности", он автоматически выводится в позицию их осмысления. Конечно, на это способен не всякий. Для этого требуется 
образованность, но именно образованные люди составляют значимую долю массовой аудитории.

Левшин С.Е.: Я заострю вопрос несколько в иную сторону. От этики - к политике. Сергей Евгеньевич, в какой мере ценности и их конструирование являются идеологическим инструментом и должны ли они им быть?

Конончук Д.В.: И я дополню - могут ли они этим инструментом не быть? Как мы можем помыслить ценности, которые невозможно использовать в качестве идеологического инструмента?

Левшин С.Е.: Да, и предположим, в государстве необходима консолидация - может ли в таком случае государство искусственно создать некий набор ценностей для того, чтобы мобилизовать население на определенные действия или настроить на определенную точку зрения?

Ячин С.Е.: Время тотальных идеологий миновало. Для современного человека, поскольку он образован и занят продуктивной (саморазвивающейся) деятельностью невозможно искусственно сконструировать ценности. Даже если вы его отключите от всех кроме одного источника информации (что сегодня уже технически невозможно) сам фракт отключения приведет к обратному эфффекту: вы его отключите и от той ценности, которую ему пытаетесь вменить. Как выразился один школьник: "вы (учителя) хотите от нас слишком многого, чтобы мы были одновременно и смышлёны и послушны".

И опять-таки - желание власть имущих поставить моральные ценности или этническую идентичность на службу своим политическим интересам является непременным. Истолковать ценность в идеологическим плане можно всегда, но только это невозможно сегодня сделать в одном русле. Я не могу представить, как разнородный комплекс ценностей современного человека можно загнать в одно русло.

Левшин С.Е.: Можно ли в связи с этим сказать, что с развитием индивидуальных, личностных, креативных ценностей будет снижаться уровень доверия к государству и идеологии?

Ячин С.Е.: Идея деидеологизации, во многом в свете глобальных проблем современности, была высказана еще в 80-х гг. прошлого века. Это был правильный прогноз, если носителем идеологии считать отдельное государство. Современное государство с развитой экономикой и политической партийной конкуренцией перестало быть субъектном определенной идеологии. Однако идеологии не исчезли, они расширили ареал своего действия до жизненных миров, охватывая отельные государственные образования. В этом смысле можно говорить о вполне определенной идеологии (точнее - идеологеме) прав человека и верховенства права для Западного мира и идеологии государственного суверенитета для восточноазиатских жизненных миров. Будучи экономически обусловленными (западный мир в значительно большей степени определен капитализацией человеческих ресурсов, а восточный - "дарами природы") эти идеологии фрормируют свои базовые ценности. Уже вопреки экономическим интересам (и для одной, и для другой стороны) эти ценности нормативно устанавливаются в виде законов государств и их союзов.

Добавлю. Если понимать, что содержание рефрлексивных практик исторически меняется, то можно заметить, что понятие идеологии и идеологические практики изменили своё содержание. Нынешнее понятие идеологии всё более обретает значение объединяющей людей ценности, ради которой они готовы предпринимать определенные коллективные действия. 
Ячин С. Е., Конончук Д. В., Киреев А. А., Левшин С. В., Котова Д. Д. Существуют ли общечеловеческие ценности? (Диалог, посвящённый семидесятилетию доктора философских наук, профессора С. Е. Ячина).

Yachin S. E., Kononchuk D. V., Kireev A. A., Levshin S. V., Kotova D. D. Are there universal human values? (Dialogue dedicated to the seventieth birthday of Doctor of Philosophy, Professor S.E. Yachin).

Для цитирования: Ячин С. Е., Конончук Д. В., Киреев А. А., Левшин С. В., Котова Д. Д. Существуют ли общечеловеческие ценности? (Диалог, посвящённый семидесятилетию доктора философских наук, профессора С. Е. Ячина) // Ойкумена. Регионоведческие исследования. 2021. № 2. C. 130-138. DOI: 10.24866/1998-6785/2021-2/130-138

For citation: Yachin S. E., Kononchuk D. V., Kireev A. A., Levshin S. V., Kotova D. D. Are there universal human values? (Dialogue dedicated to the seventieth birthday of Doctor of Philosophy, Professor S.E. Yachin). // Ojkumena. Regional researches. 2021. № 2. P. 130-138. DOI: $10.24866 / 1998-6785 / 2021-2 / 130-138$ 